\title{
USE OF DIFFERENT TECHNIQUES OF VISUALIZATIONS IN THE TRAINING OF ENGINEERING SPECIALISTS: NEEDS VERSUS APPROACHES
}

\author{
Zoja Veide \\ Riga Technical University, Latvia \\ Veronika Strozheva \\ Riga Technical University, Latvia
}

\begin{abstract}
The quality of engineering education is closely related to the development of spatial skills of students and the ability to create and read the drawings. Visualization improves the efficiency of the information; as for visualization of geometric tasks of graphical subjects, it helps students faster comprehend complex spatial problems and solve the given exercises.

The given article describes the study of the methodology of teaching graphical subjects from the point of view of methods of representations of education materials, the degree of inspiration and engagement of students in learning activities. The research was conducted in Latvia, Lithuania, Spain, Germany and Poland within the project "Contemporary Approach to the Development of Spatial Comprehension through Augmented Reality Content" (SPACAR).

Keywords: Augmented Reality, Engineering graphical subjects, spatial skills, Visualization Techniques.
\end{abstract}

\section{Introduction}

By 2025, two billion of the global population is going to be made up by the youngest generation: Generation Alpha. Generation Alpha are children born between 2010 and 2025. This is the first generation entirely born in the 21st century. Generation Alpha use technology, smartphones, tablets, and computers naturally. They haven't known life without the Internet or video games.

Alpha children are accustomed to gaining knowledge through action, screen touch, and experience. Schools must provide an adequate environment that enhances this type of learning. Such an environment requires changes and a new approach to education at all levels, the creation of training programs widely using various methods of visualizing educational material.

Thanks to the development of technologies, such types of visualizations as augmented, virtual and mixed reality (AR / VR / MR), it has become possible to include AR and VR content in the educational process, which can make learning 
Veide \& Strozheva, 2021. Use of Different Techniques of Visualizations in the Training of Engineering Specialists: Needs Versus Approaches

more effective, faster and more fun (da Silva, Teixeira, Cavalcante, \& Teichrieb, 2019). From mathematics to chemistry to biology, AR can be incorporated into just about any subject.

In other words, this is one of the best ways an educator can use to engage and motivate students (Dobelis, Sroka-Bizon, \& Branoff, 2019). Augmented Reality technology expands the physical world; it adds layers of digital information onto what we can see with the naked eye. It augments our surrounding by adding sound, video, and graphics. AR is a useful pedagogical tool in teaching because it is grounded on efficient teaching and learning models such as constructivist learning, situated learning, and inquiry-based learning (Yousef, 2021). Visualization techniques are also used to improve collaborative learning that incorporates a social component in distance education to minimize the disadvantages of studying in solitude (Anaya, Luque, \& Peinado, 2016).

This article reviews the results of surveys that were conducted for graphical subjects of engineering students within the project "Contemporary Approach to the Development of Spatial Comprehension through Augmented Reality Content". The aim of this project to develop the didactic toolkit which includes set of practical exercises with $3 \mathrm{D}$ objects prepared for the use into AR environment.

\section{Methodology}

The study involved partners from five countries participating in the project SPACAR. The survey was conducted from 15/12/2019 to 15/02/2020 in Latvia, Lithuania, Spain, Germany, and Poland. The following partners participated in the Needs Analysis: Vilnius Builders Training Centre (Lithuania); Riga Technical University (Latvia); Warsaw Technical University (Poland); Polytechnic university of Valencia (Spain); Siauliai vocational education and training centre (Lithuania); SneakyBox Information technology company (Lithuania); Jugendförderverein Parchim/Lübz e.V. (Germany); DECROLY Vocational Education and Training college (Spain).

The survey was carried out using survey administration application Google Forms. In this study, questionnaires with closed-ended questions were used to analyse needs. The adapted questionnaire included questions with multiple options so that respondents can choose the answers true for them.

620 students at vocational schools, secondary schools, colleges, higher schools and universities participated in the survey. The study also included 195 educators of schools, colleges and higher education institutions.

The target group of Latvian students was 224 people, the Spanish group was 214 people, 113 students participated from Poland, a group of Lithuanian students was 50 people and 19 students from Germany completed the questionnaires. 
$75,8 \%$ of the participants of this target group were male, while $24,2 \%$ of them were female. The distribution of survey participants by country in the teacher group was as follows: 86 participants from Spain, 42 from Poland, 26 from Lithuania, 25 from Latvia, 16 from Germany. Of all the educators surveyed, $55.9 \%$ were male and $44.1 \%$ were female.

\section{Results}

620 students participated in the survey, among which 224 were from Latvia, 214 - from Spain, 113 - from Poland, 50 - from Lithuania, and 19 - from Germany. Approximately three quarters of the respondents were male, and one quarter were female.

The distribution by educational institution was not even. Most of the respondents, i.e. 61.5\%, were university students (Fig. 1). For the further analysis the responses that did not contain answers to all the questions or contained (irrelevant) answers that did not correspond to the questions were excluded from consideration. The responses were grouped by educational institution where the respondents study - 'University', 'Higher School', 'Vocational School', 'College' and 'Secondary School'. Those responses which were marked as 'Other' were classified to one of aforementioned groups which, in our opinion, was the most relevant.

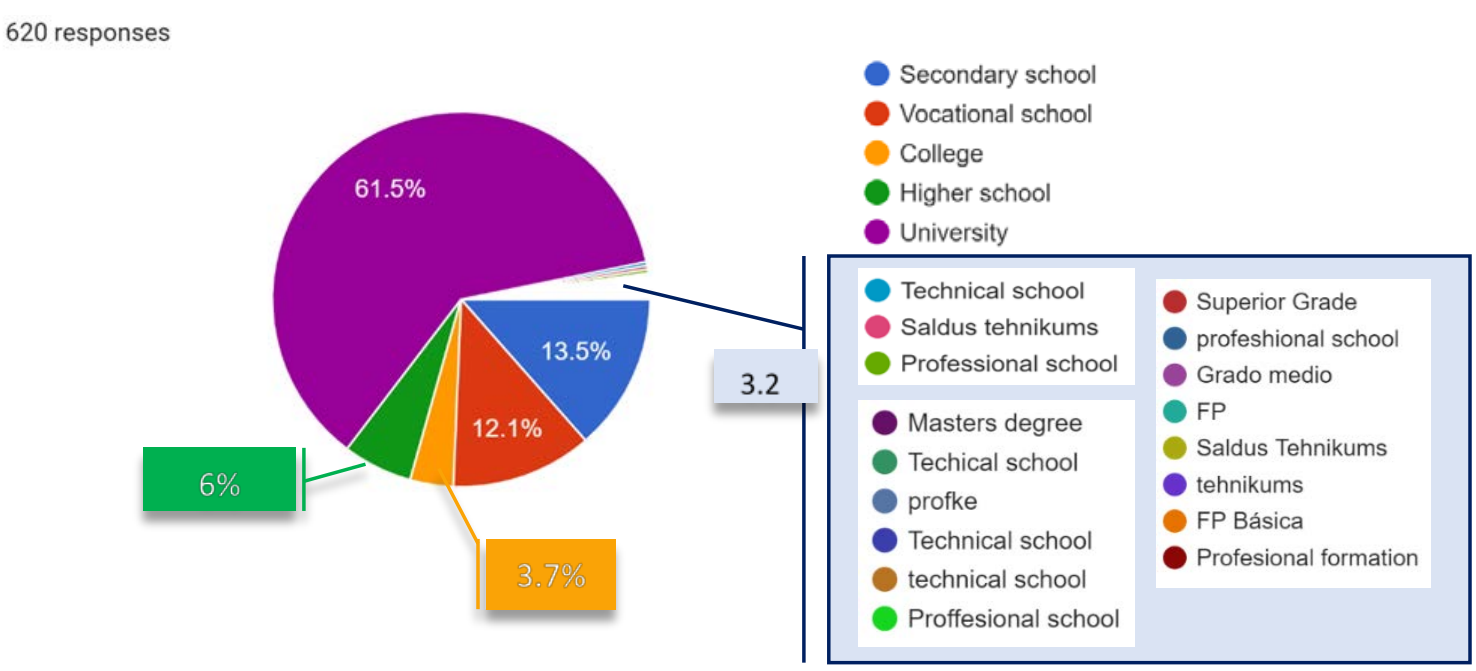

Figure 1 The Distribution by Educational Institution of Students Participated in Study

The chart below (Fig. 2) reflects the percentage distribution of teaching materials used in corresponding educational institutions. It can be concluded that PowerPoint presentations are the most popular teaching tool. On the other hand, AR and VR technologies are the least common. 
Veide \& Strozheva, 2021. Use of Different Techniques of Visualizations in the Training of Engineering Specialists: Needs Versus Approaches

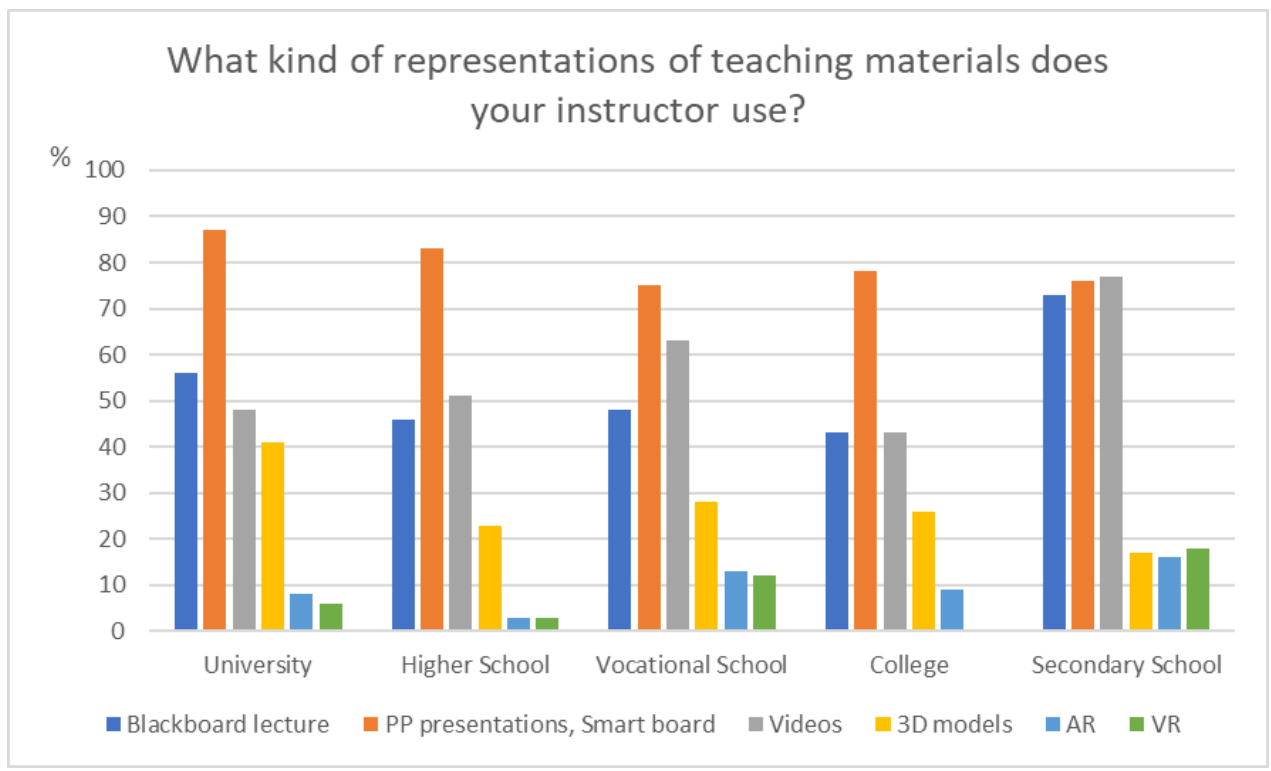

Figure 2 Students Answers on the Question "What kind of representations of teaching materials does your instructor use?"

The following charts (Fig. 3) reveal that students using mostly computers and smartphones.

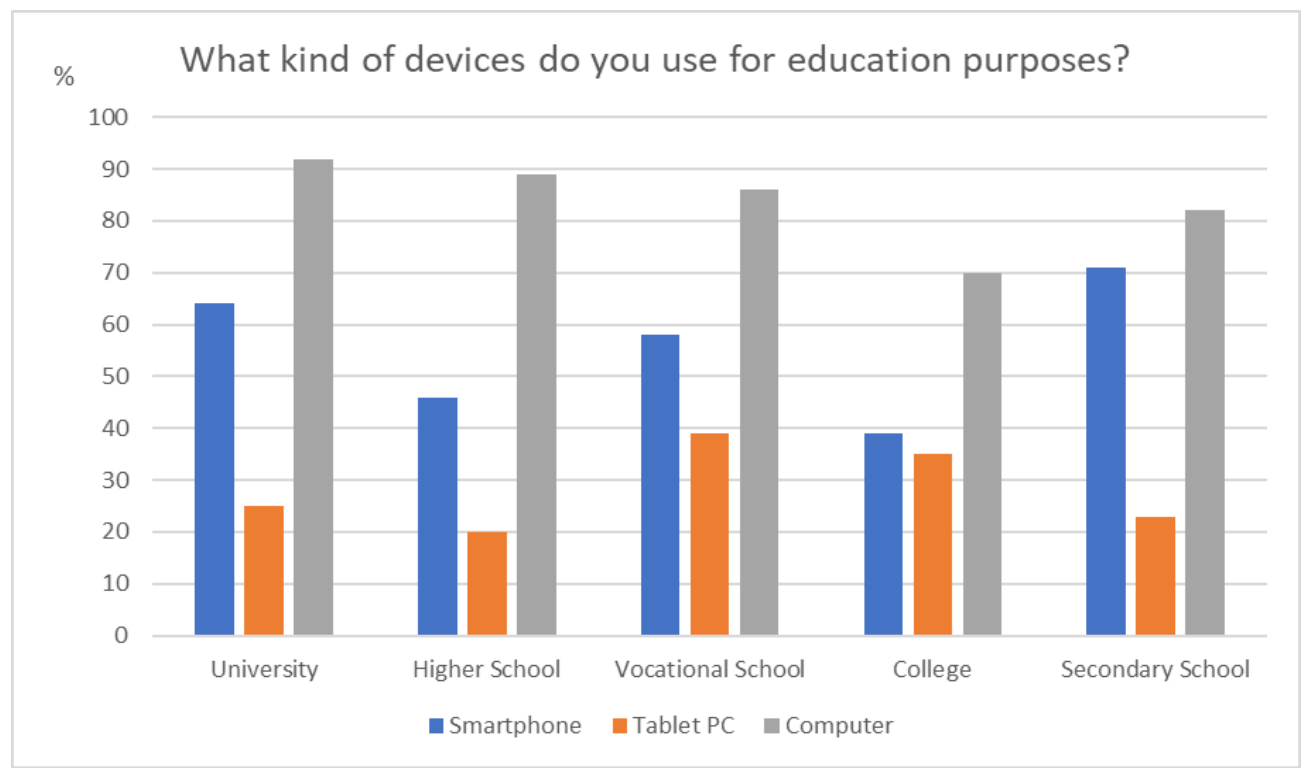

Figure 3 Students Answers on the Question "What kind of devices do you use for education purposes?”

To identify the degree of inspiration and engagement of students in learning activities depending on a different kind of representation of teaching materials, the questions presented on figure 3 were included in the survey. According to the results, students prefer teaching using visualization and 3D presentation techniques over traditional lectures, they are more motivated to learn new subject 
content, and the content is more understandable for them when visualization techniques are used in teaching the subject.
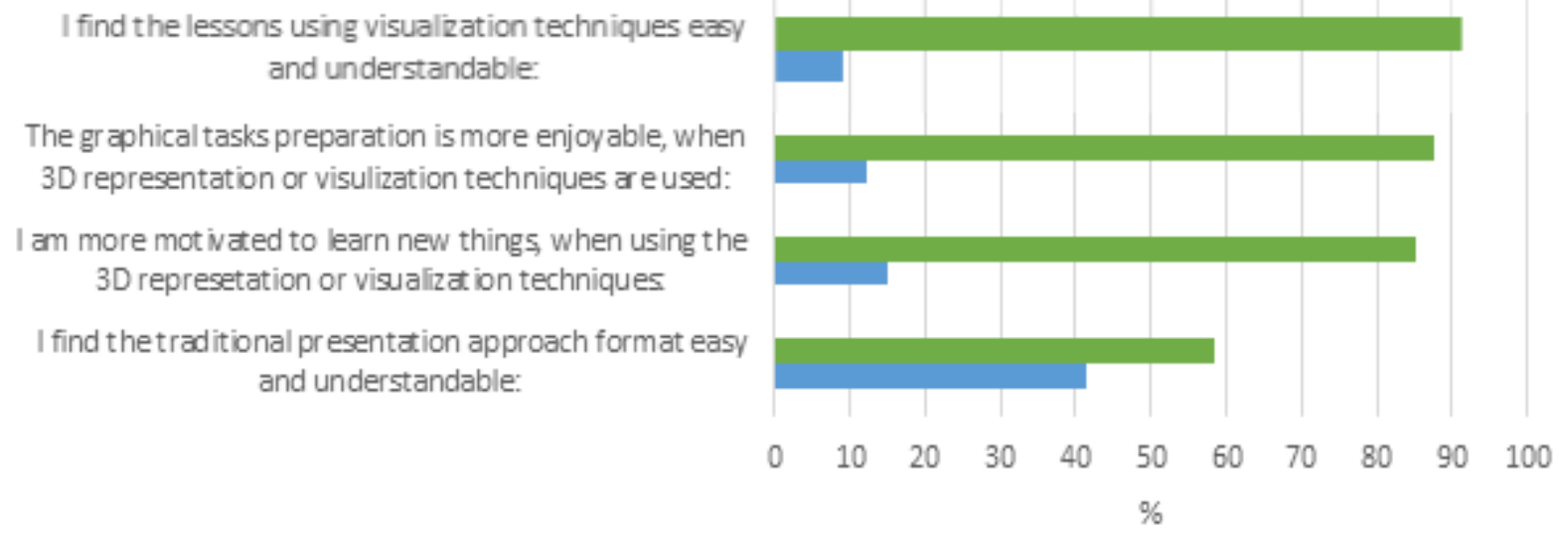

Figure 4 Student Opinion on the Following Statements: I find the lessons using visualization techniques easy and understandable, The graphical tasks preparation is more enjoyable, when $3 D$ representation or visualization techniques are used, I am more motivated to learn new things when using $3 D$ representation or visualization techniques,

I find the traditional presentation approach format easy and understandable.

Students' opinion about having difficulties during constructing orthographical views, axonometric projections and 3D objects from flat of paper is presented in figure number 5. Most of the students answered that they did not have such difficulties.

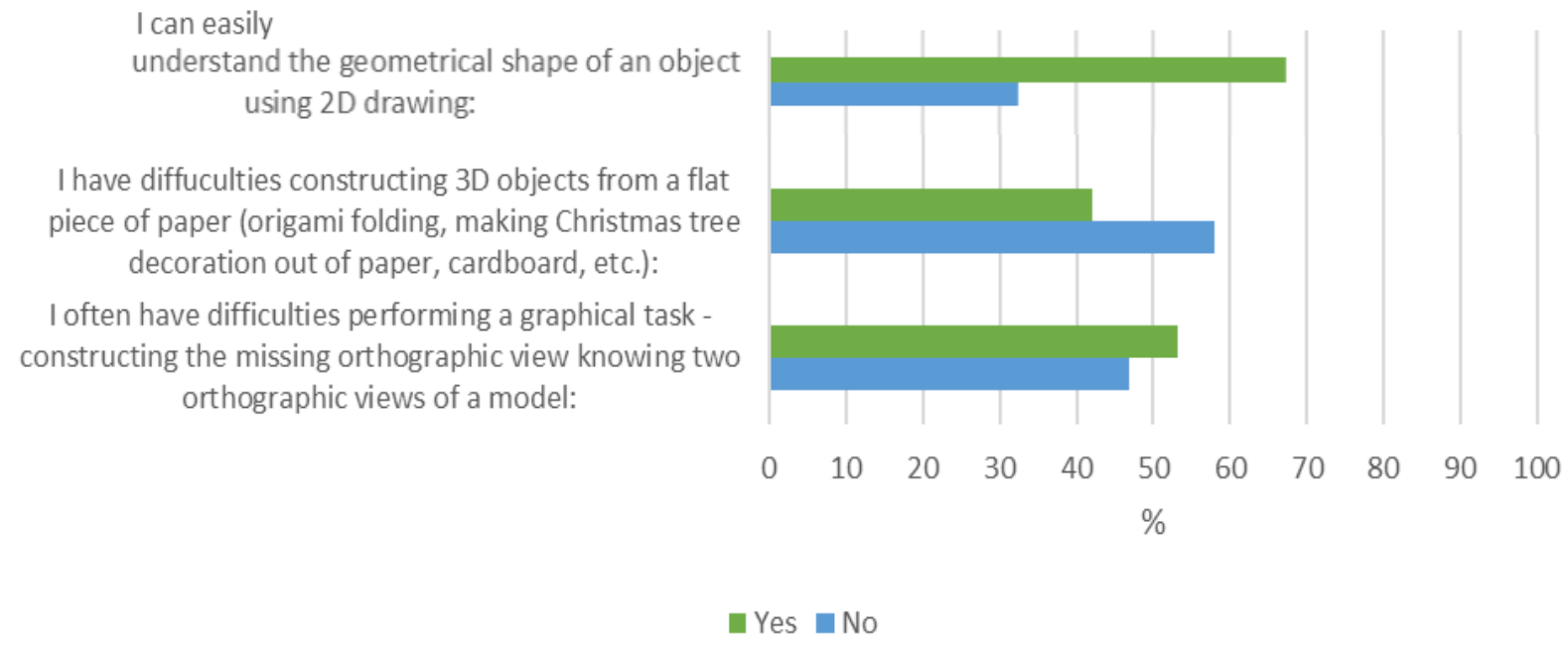

Figure 5 Student Opinion on the Following Statements: I can easy undertand the geometrical shape of an object using $2 \mathrm{D}$ drawing, I have difficulties constructing $3 D$ object from flat piece of paper, I often have difficulties performing graphical tasks - constructing missing orthographic view knowing two orthographic views of model. 
Veide \& Strozheva, 2021. Use of Different Techniques of Visualizations in the Training of Engineering Specialists: Needs Versus Approaches

195 instructors participated in the survey, among which 86 were from Spain, 42 - from Poland, 26 - from Lithuania, 25 - from Latvia, and 16 - from Germany. The distribution by educational institution where they work was not even. Most of the respondents, i.e. 35.9\%, were university instructors (Fig. 6).
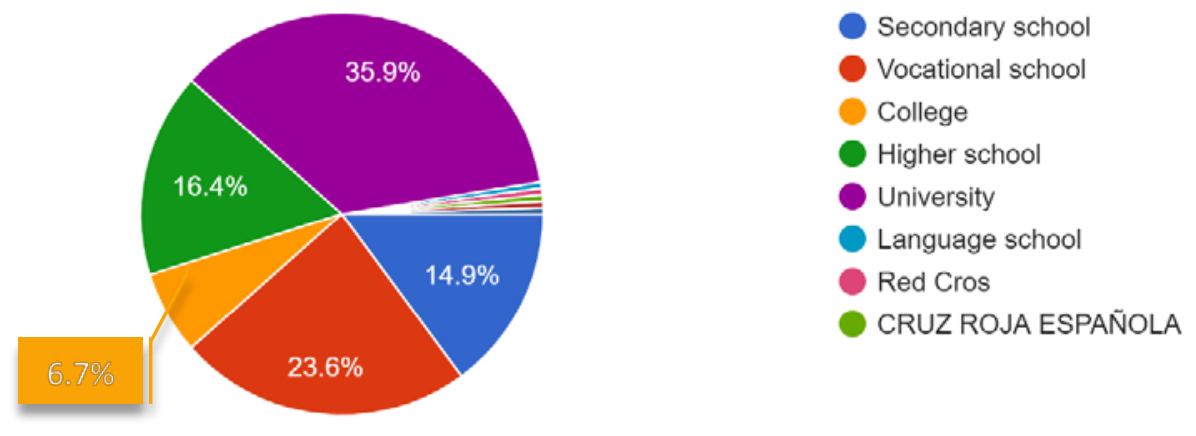

Figure 6 The Distribution by Educational Institution Where Work Instructors Participated in the Study

The respondents were grouped by educational institution where the respondents work - 'University', 'Higher School', 'Vocational School', 'College', 'Secondary School' and 'Other'. The charts below (Fig. 7) suggest that the most common tools used by instructors are PowerPoint presentations and Smart boards, blackboard lectures and videos respectively.

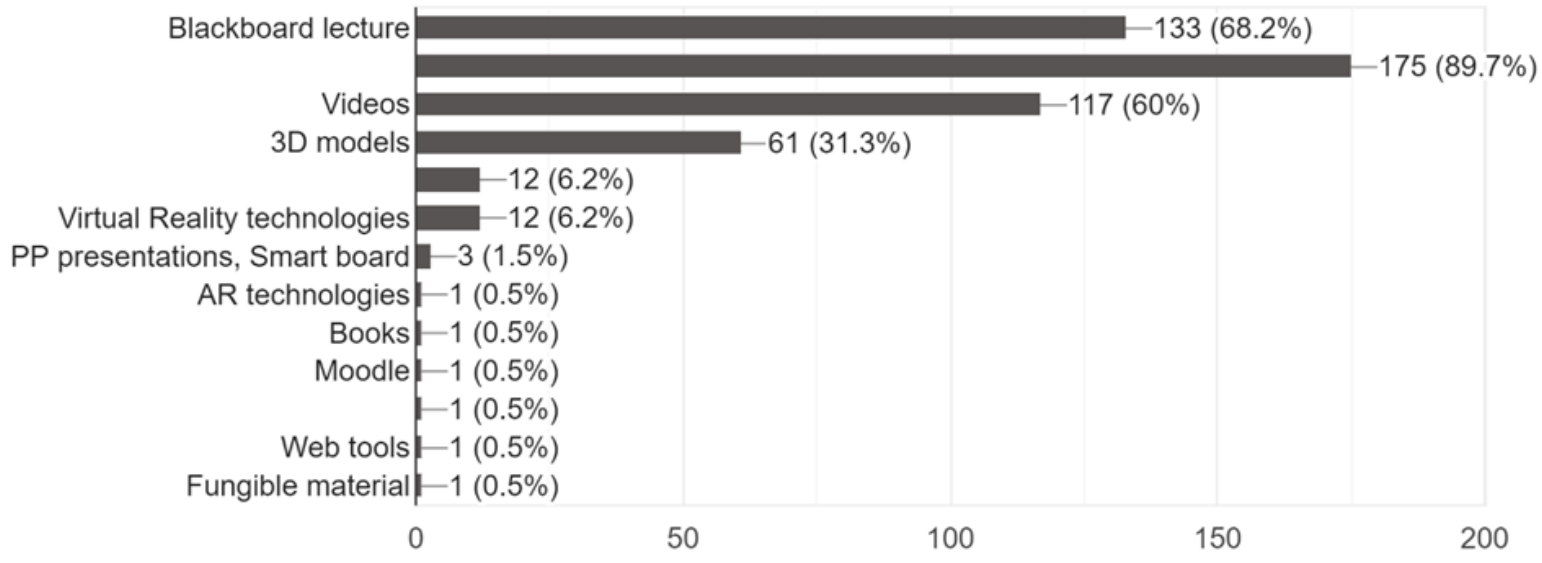

Figure 7 Instructors Answers on the Question "What kind of representation of teaching materials do you use?”

The instructors also claim that most students use computers for educational purposes on their lessons (Fig. 8). These answers are consistent with the answers received from students. The opinion of instructors about whether students have 
difficulties in completing graphic assignments differs from the opinion of students - most educators consider that students have difficulties performing graphical tasks (Fig. 9). The instructors suppose that lessons will be easy and understandable if visualization techniques are used.

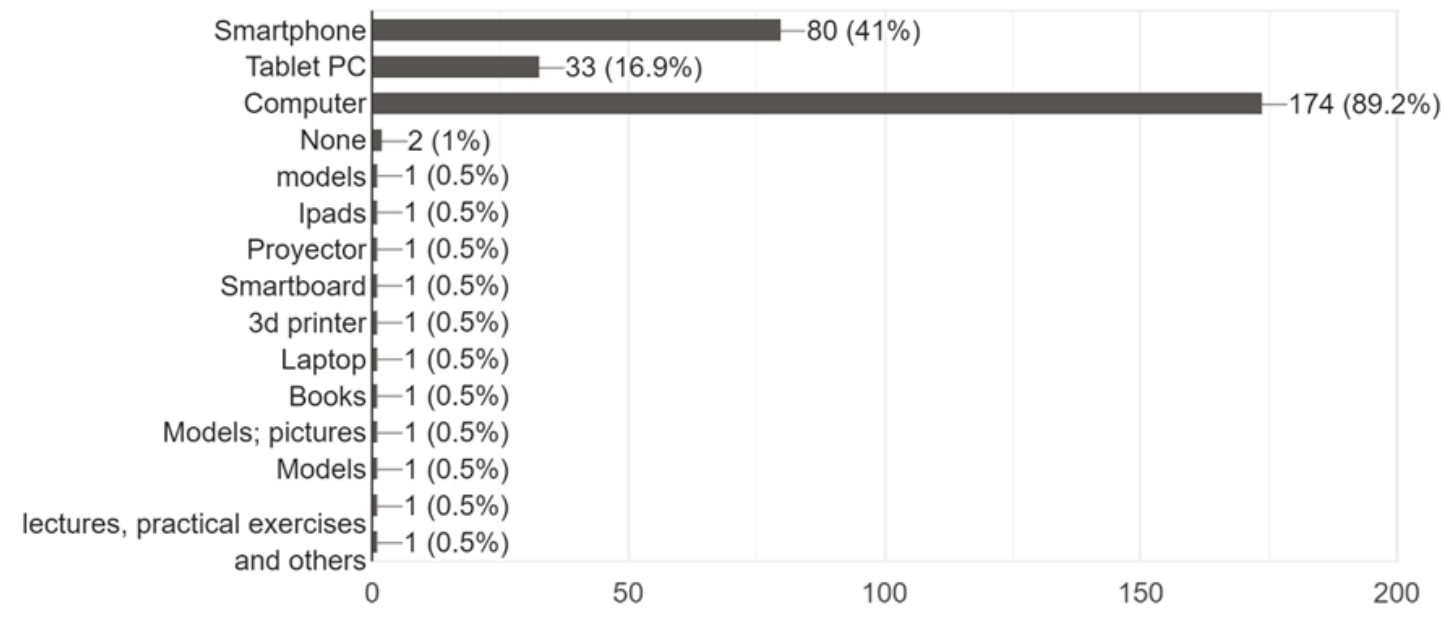

Figure 8 Instructors answers on the question "What kind of devices do students use for education purposes on your lessons?”

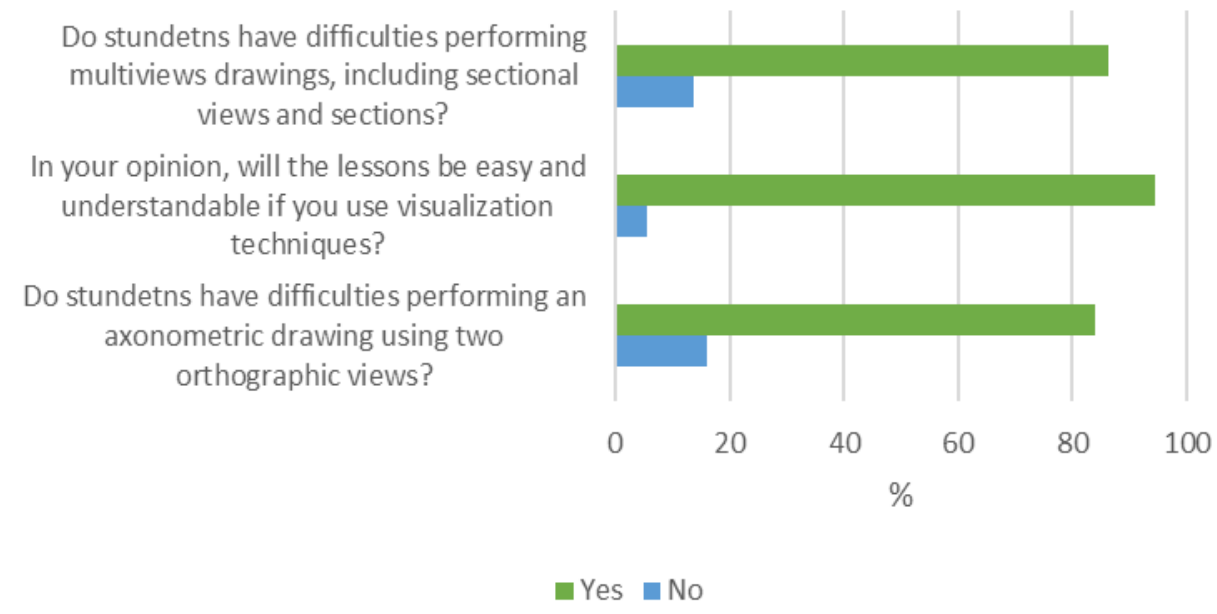

Figure 9 Instructors answers on the questions "Do students have difficulties performing multiviews drawing, including sectional views and sections?", "In your opinion, will the lessons be easy and understandable if you use visualization techniques?", "Do students have difficulties performing axonometric drawing using two orthographic views?”

\section{Discussions}

Based on the data obtained, the following conclusions can be drawn. In all countries of the project participants, the most common teaching method is based on the use of Blackboard lectures and PowerPoint presentations. This may indicate a lack of educational materials using augmented reality technologies. 
Veide \& Strozheva, 2021. Use of Different Techniques of Visualizations in the Training of Engineering Specialists: Needs Versus Approaches

This makes it necessary to create didactic material using AR. In addition, almost $70 \%$ of teachers find traditional teaching methods to be time-consuming. The introduction of visualization technologies into the educational process can greatly facilitate the learning process and provide an opportunity for the development of new teaching methods (Ozdemir et al., 2018). However, it should be borne in mind that the implementation of visualization methods is difficult due to the time required to find suitable examples, to learn new tools, the time required to develop visualizations and adapt them to the course content (Klerkx, Verbert, \& Duval, 2014).

The majority of students (over 60\%) find traditional teaching methods boring and not conducive to increasing interest in learning. An even larger number of students (about 90\%) prefer teaching using visualization and three-dimensional presentation methods to traditional lectures and are of the opinion that this teaching method makes the teaching material more understandable. 94\% of teachers also confirm this. According to the students, they study better, are more motivated to learn new content of the subject and are more pleased to complete graphic assignments when visualization methods are used in teaching the subject. This suggests that the introduction of teaching materials using 3D object visualization (AR/VR) in the educational process will increase student motivation (Sun, Siklander, \& Ruokamo, 2019) and will contribute to academic performance (Garzón, \& Acevedo, 2019).

Despite the fact that the majority of students believe that they have no difficulty in performing graphic tasks, such as building a third type of object, knowing two spelling views, the vast majority of teachers (about 85\%) believe that students have difficulty in constructing a multi-view drawing. axonometric projections and sections. In addition, $42.1 \%$ of the students noted that they have difficulty constructing three-dimensional objects from a flat sheet of paper. All this may indicate a low level of spatial abilities of students. Spatial ability is especially important to student success in some engineering disciplines such as computing, mathematics, engineering drawing, and computer design, as well as solving geometric problems (Branoff \& Dobelis, 2012). According to scientific research, the use of augmented reality technology in teaching graphic engineering subjects increases the level of spatial skills (Martín-Gutiérrez et al.,2015). All this confirms the need to develop modern didactic tools in order to increase the level of spatial abilities of future engineers. 


\section{Conclusions}

Currently, educational institutions are not provided with an enough educational materials used visualization technologies.

The widespread use of various visualization methods is complicated by the fact that it is necessary to spend additional time on creating visualization and adapting to the content of the academic subject. A positive impact on the educational process can only be achieved if visualization techniques are fully integrated into the classes.

It is necessary to introduce into the educational process study materials using various types of visualization of the content of graphic tasks, including visualization of objects in an augmented reality environment in order to facilitate the students understanding of the teaching materials and motivate to study (Veide, \& Stroževa, 2019).

The level of spatial abilities of students is not high enough. The AR application enables faster comprehension of complex spatial problems and relationships (Auliya, \& Munasiah, 2020) and allows improve spatial abilities. If students try to improve their spatial skills by AR training academic performance rate will be greater.

\section{References}

Anaya, A. R., Luque, M., Peinado, M. (2016). A visual recommender tool in a collaborative learning experience. Expert Systems with Applications, 45(C). DOI: 10.1016/j.eswa.2015.01.071

Auliya, R.N., \& Munasiah, M. (2020). Augmented Reality Affects Students' Attitude and Conceptual Understanding in Learning 3D Geometry. Journal Pendidikan Indonesia, 9(2). DOI: $10.23887 /$ jpi-undiksha.v9i2.17480

Branoff, T., \& Dobelis, M. (2012). The Relationship between Spatial Visualization Ability and Students' Ability to Model 3D Objects from Engineering Assembly Drawings. Engineering Design Graphics Journal of the ASEE, 76(3), 37-43.

Dobelis, M., Sroka-Bizon, M., \& Branoff, T. (2019). How to Boost the Students' Interest to Engineering Graphics? IOP Conference Series: Materials Science and Engineering. Vol.660: 4th International Conference on Innovative Materials, Structures and Technologies (IMST 2019), 1757-899X. DOI:10.1088/1757-899X/660/1/012013

Garzón, J., \& Acevedo, J. (2019). Meta-analysis of the impact of Augmented Reality on students’ learning gains. Educational Research Review, 27, 244-260, Retrieved from https://doi.org/10.1016/j.edurev.2019.04.001

Klerkx, J., Verbert, K., Duval, E. (2014). Enhancing Learning with Visualization In: J. Michael (Ed), Techniques. Handbook of Research on Educational Communications and Technology (791-807), Springer Science+Business Media, New York, DOI: 10.1007/978-1-4614-3185-5_64 
Veide \& Strozheva, 2021. Use of Different Techniques of Visualizations in the Training of Engineering Specialists: Needs Versus Approaches

Martín-Gutiérrez, J., Contero, M., \& Alcañiz, M. (2015). Augmented Reality to Training Spatial Skills, Procedia Computer Science, 77, 33-39, Retrieved from https://doi.org/10.1016/j.procs.2015.12.356

Ozdemir, M., Sahin, C., Arcagok, S., \& Demir, M. (2018). The Effect of Augmented Reality Applications in the Learning Process: A Meta-Analysis Study. Eurasian Journal of Educational Research, 74, 165-186.

da Silva, M., Teixeira, J., Cavalcante, P., \& Teichrieb, V. (2019). Perspectives on how to evaluate augmented reality technology tools for education: a systematic review. J Braz. Comput. Soc., 25(3). Retrieved from https://doi.org/10.1186/s13173-019-0084-8.

Sun, L. P., Siklander, P., \& Ruokamo, H. (2019). How to trigger students' interest in digital learning environments: A systematic literature review. Seminar.Net, 14(1), 62-84. Retrieved from https://journals.hioa.no/index.php/seminar/article/view/2597

Veide, Z., \& Stroževa, V. (2019). Triggering the Students' Positive Attitude for the Studies of Engineering Graphics Courses through the Augmented Reality Content. Environment. Technology. Resources: Proceedings of the 12th International Scientific and Practical Conference, 2, 242-246. DOI:10.17770/etr2019vol2.4184

Yousef, A.M.F. (2021). Augmented reality assisted learning achievement, motivation, and creativity for children of low-grade in primary school. Journal of Computer Assisted Learning. DOI: 10.1111/jcal.12536 